IV Congreso Internacional Estética y Política Poéticas del desacuerdo para una democracia plural 16 y 17 de octubre. Valencia

Doi: http://dx.doi.org/10.4995/CEP4.2019.10313

\title{
Filmar el desacuerdo. El cine de Iris Zaki
}

\section{Rubén Marín Ramos}

(Universitat Politècnica de València, rumara1@ alumni.upv.es )

\begin{abstract}
This article deals with the videographic work of the Israeli Iris Zaki, a documentary filmmaker who uses an original method of work with which he manages to establish dialogic spaces in closed communities. A particular strategy in which highlights the temporary abandonment of the role of filmmaker - Enter to work in different establishments and, once inside, set up a minimum device, in which the filmmaker leaves the camera "abandoned" (recording without control), and showing, practically, the same plane throughout the film. With this, Zaki focuses all his attention on the conversations she has with subjects from different groups or communities around her, whether they are: Orthodox Jews in London, Arabs in Haifa, or Israeli settlers in a settlement in the West Bank, interfering as little as possible in the scene and getting them to intervene with greater sincerity and spontaneity in front of the camera.
\end{abstract}

In Zaki's works, the ethnographic and autobiographical part are diluted in one, her personal history is irremediably fastened to the communities she films; they share the same territory, the same historical circumstances, etc., but, in addition, Zaki appears in all her films. She also answers, asks, reflects ... in front of the camera, so that at the same time that we know those "others" we also do it with the same filmmaker.

Between artist practice and activism, the amateur and the experimental, Zaki's pieces are a good example of the new formulas that are renewing the cinema's panorama of the real and that, due to their condition as makers, can be especially interesting for new filmmakers who lack the technical and human resources or for those interested in documentary cinema of a minimalist nature.

Keywords: Ethnographic documentary, film device, Arab-Israeli conflict, first person documentary, closed communities.

\section{Resumen}

El presente artículo aborda la obra videográfica de la Israelí Iris Zaki, documentalista que emplea un singular método de trabajo con el que logra establecer espacios dialógicos en comunidades cerradas. Una particular estrategia en la que destaca el abandono temporal del rol de cineasta - para entrar a trabajar en diferentes establecimientos y, una vez dentro, ubicar un dispositivo mínimo - en la que la directora deja la cámara "abandonada"(grabando sin nadie que la controle) - mostrando, prácticamente durante toda la película el mismo plano. Con esto Zaki centra toda la atención en las conversaciones que mantiene con sujetos de diferentes grupos o comunidades de su entorno, ya sean: judios ortodoxos en Londres, árabes en Haifa, o colonos Israelís en un asentamiento en Cisjordania, interfiriendo lo menos posible en la escena y consiguiendo que intervengan con una mayor sinceridad y espontaneidad frente a la cámara.

En los trabajos de Zaki la parte etnográfica y la autobiográfica se diluyen en una, su historia personal está, irremediablemente, sujeta a las comunidades que filma; comparten el mismo territorio, las mismas circunstancias históricas, etc., pero, además, Zaki aparece en todas sus películas. Ella también responde, pregunta, reflexiona... delante de la cámara, por lo que a la vez que conocemos a esos «otros», conocemos también a la misma directora.

Entre la práctica artística y el activismo, lo amateur y lo experimental, las piezas de Zaki son un buen ejemplo de las nuevas fórmulas que están renovando el panorama del cine de lo real y que, por su condición 
hacedora, pueden ser especialmente interesantes para nuevos creadores que carezcan de los recursos técnicos y/o humanos o para aquellos interesados por el documental de índole minimalista.

Palabras clave: Documental etnográfico, dispositivo fílmico, conflicto árabe-israelí, documental en primera persona, comunidades cerradas.

\section{Filmar el desacuerdo}

Todos los proyectos de Iris Zaki nacen de la propensión por conocer a un "otro" - clásico objetivo del cine etnográfico con la singularidad de que este "otro" no es algo extraño o lejano a ella, sino personas o comunidades con las que comparte identidad, lengua o territorio: judíos ultra ortodoxos en Londres, árabes en Haifa, colonos israelís en Cisjordania. Esto se entiende dada la compleja segmentación de la población en su país natal, donde las diferentes comunidades en la que se divide apenas tienen interacción entre ellas. Es en este deseo de conocer a estas comunidades que para ella son cercanas y, a la vez, lejanas, donde la realizadora encuentra la motivación para hacer sus películas. Pero no pretende aproximarse a ellas entendiéndolas como algo monolítico o cerrado, sino que quiere acercarse a las personas que las componen, convencida de que, a pesar de tener sus propios rituales y dogmas en común, cada persona tiene su propia motivación personal e interpreta los mismos códigos de diferentes maneras. De forma que, lejos de los clichés y de los recelos que ha escuchado a lo largo de su vida, la realizadora, espera poder encontrar más cosas en común de lo que pueda parecer en un primer momento. No obstante, Zaki no se conforma con esto, quiere además confrontar su visión de las cosas con la de ellos. Sus ideas, opiniones, así como su estilo de vida, de una "izquierdista de ciudad" (como se autodefine de cara a los colonos en, Unsettling (2018), su última película) y lo hace, no con un fin autocomplaciente, sino porque quiere que cada una de las personas con quien se sienta a dialogar en sus películas, haga también el esfuerzo de ponerse en el lugar del otro. Es por esto que su rol no es únicamente de escucha o neutral, sino que está dispuesta a discrepar y rebatir, aunque tenga que ponerse a sí misma como ejemplo. Mostrar el desacuerdo, es por lo tanto el primer paso para, al menos, intentar originar verdaderos espacios dialógicos, donde, más allá de pretender mostrar cómo viven o piensan los miembros de estas comunidades, su trabajo pueda ser útil para encontrar lugares comunes entre posturas e ideas tan dispares y enfrentadas. Y como podemos ver en sus películas, sorprendentemente, hasta en los lugares más radicalizados, siempre hay quien muestra algo de cordura, alguien que está dispuesto a ceder, que entiende la posición del otro y que da motivos, al menos, para seguir intentándolo.

\section{Descuidar el proceso Fílmico}

Eliminar el peso del dispositivo ha sido una de las primeras preocupaciones y retos del cine documental. Desde el trabajo en estudio con las pesadas cámaras de $35 \mathrm{~mm}$ hasta la aparición de la tecnología digital, se han sucedido multitud de transformaciones en el soporte del cine que progresivamente han posibilitado un acercamiento más directo a lo real, permitiendo influenciar menos y dar más espontaneidad a la puesta en escena. En la segunda parte del influyente film de Jean Rouch y Edgar Morin, Chronique d'un été (1960), los protagonistas reconocían haberse sentido intimidados por las cámaras hasta el punto de no reconocerse en la película. La ligereza y el tamaño de las nuevas cámaras digitales, así como los muchos otros dispositivos para capturar imágenes que hoy tenemos a nuestro alcance, nos permiten capturar, como nunca antes, lo que ocurre frente a la cámara. Los trabajos de Iris Zaki se caracterizan por el empleo de una particular estrategia con la que, gracias a la ligereza y las nuevas temporalidades que ofrece el dispositivo digital, la realizadora consigue introducirse en el día a día de diferentes grupos o comunidades con el fin de establecer espacios dialógicos, donde elimina casi por completo la presencia del dispositivo fílmico. Este particular modo de trabajo se dio de forma azarosa en su primer cortometraje My Kosher Shifts (2011), mientras Zaki trabajaba como recepcionista en un hotel de judíos ortodoxos en Londres para poder hacer frente a los costes de sus estudios de máster en cine documental. La directora advirtió allí que, por primera vez, podía conversar e incluso debatir sobre algunas cuestiones con sus paisanos. Esto animó a Zaki a filmar las conversaciones que tenía con los clientes y, con el fin de reducir la presencia del dispositivo fílmico al máximo y mantener la dinámica intimista entre recepcionista y cliente, la entonces inexperta realizadora, 
estableció un dispositivo mínimo - colocando una única cámara sobre un trípode detrás de ella - dando lugar a lo que ella llama "técnica de la cámara abandonada" (Zaki, 2017). De esta forma, toda la atención se centra en la interacción entre la realizadora y los clientes del hotel.
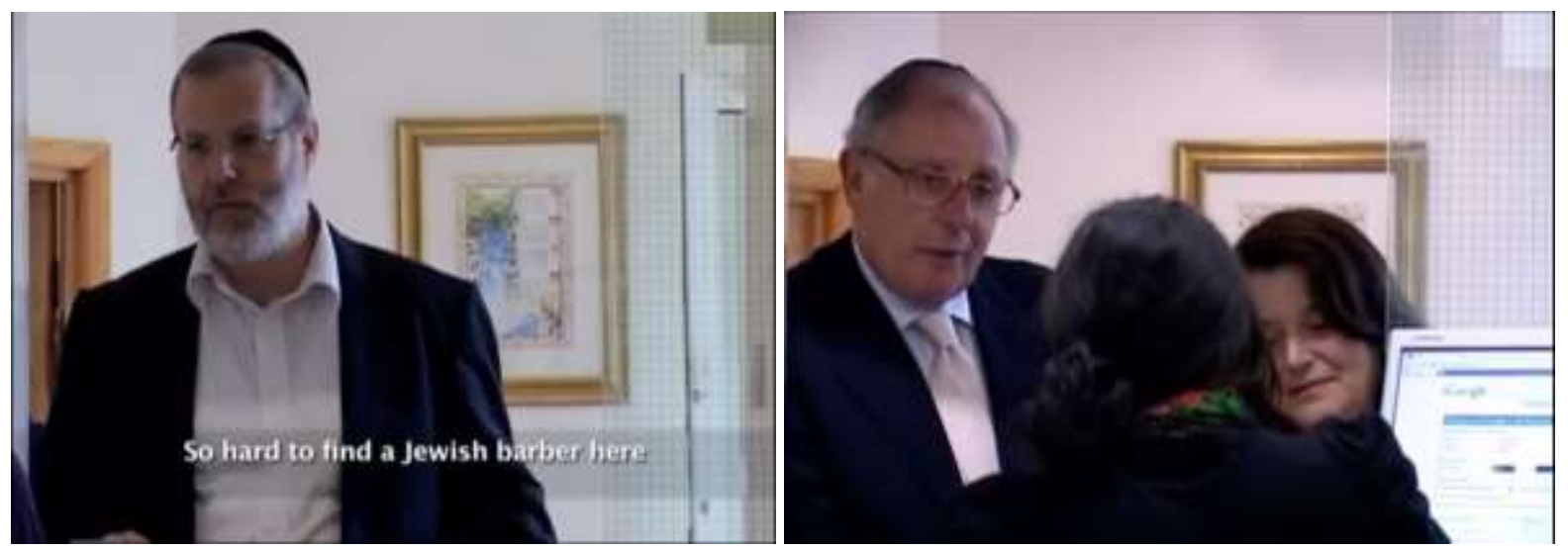

Fig 1. y Fig 2. Fotogramas de My Kosher Shifts (2011)

\subsection{Buscar el lugar adecuado}

Uno de los casos más conocidos, en las últimas décadas, de un director de cine que renuncia de forma voluntaria a trabajar con su equipo - técnico y humano - para conseguir introducirse en la cotidianeidad de una persona o comunidad, es el del portugués Pedro Costa. El lisboeta, para filmar $O$ quarto da vanda (2000), decidió prescindeir de sus colaboradores y técnicos y, con únicamente una cámara de vídeo, se sumergió en la vida de Vanda, protagista del film. Otro ejemplo similar, pero donde el director no tuvo que renunciar a nada, porque carecía de ello, y que Zaki menciona como referente en su tesis doctoral, es la película Lift (2001) de Marc Isaacs. Un documental filmado íntegramente dentro del ascencor de un rascacielos en el este de Londres. En el que su director permaneció dos meses, durante diez horas al día, subiendo y bajando con los residentes del edificio con su cámara al hombro apuntando hacia ellos. Es esta misma estratégica de infiltrarse en un espacio determinado donde partir con ventaja para filmar a ese "otro", lo que se encontró Zaki en el hotel de Londres que dio como fruto su primer cortometraje ya citado, My Kosher Shifts.

Cuantro años más tarde, ya en el transcurso de su tesis doctoral, Zaki volvió a repetir la misma fórmula en Women in Sink (2015), esta vez en su ciudad natal, Haifa, y ahora de forma premeditada. Zaki entró a trabajar en un salón de belleza propiedad de una cristiano-palestina. Allí, al cabo de un mes, la realizadora colocó sobre uno de las sillones para cortar el pelo una barra de aluminio y, enganchada a ésta, una cámara que capturaba - en un plano cenital - las cabezas de las mujeres mientras la misma directora les lavaba el cabello. El resultado, Women in Sink, un film de 38 minutos construido casi exclusivamente con un único plano (cenital) de cabezas parlantes e interrumpido, fugazmente, por algunas tomas cortas de la peluquería en su día a día. 


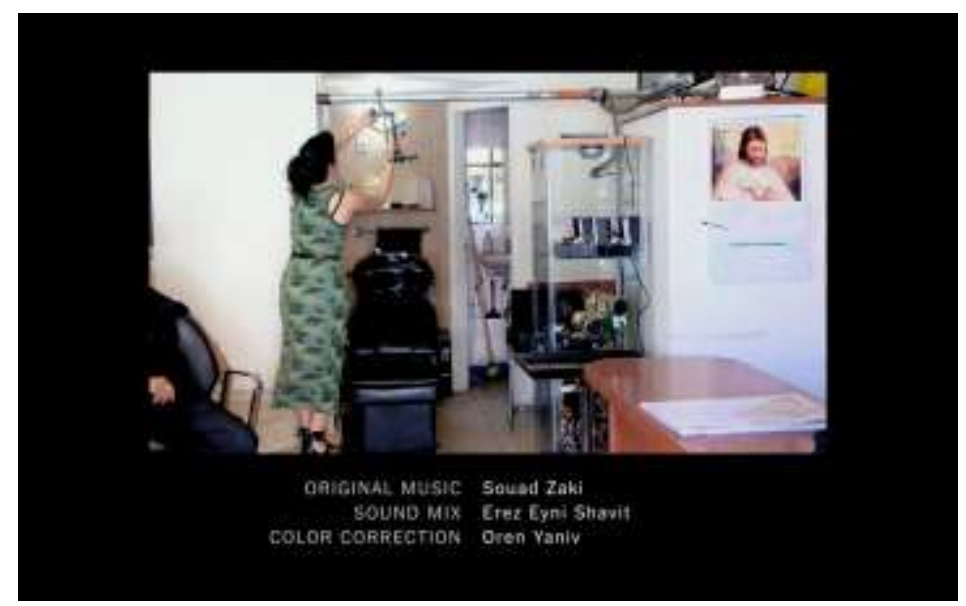

Fig 3. Fotograma de Women in Sink (2015)

\subsection{Un abandono temporal}

Como en My Kosher Shifts, Zaki entra a trabajar en un establecimiento antes de comenzar a rodar, de esta forma parece dejar de lado (al menos temporalmente) su papel de cineasta. Este modo de actuar recuerda a las prácticas artísticas surgidas en los años sesenta vinculadas a la performance participativa, donde los artistas se apropiaban de formas sociales como, por ejemplo; "bailar salsa (Hélio Oiticica) o funk (Adrian Piper); beber cerveza (Tom Marioni); discutir filosofía (Ian Wilson) o política (Joseph Beuys); organizar un mercadillo (Marta Rosler)(...)” (Bishop, 2006). Aquí, también Zaki desplaza de su rol de directora para conseguir introducirse en el día a día de una comunidad, en este caso de mujeres palestinas residentes en Haifa que, de otra forma, hubiera tenido complicado para conocer y filmar. Además, el hecho de que se limite prácticamente a un solo plano, le permite desprenderse de toda la parte artesanal o técnica ligada a la tradición cinematográfica para centrarse, en su lugar, en los procedimientos procesuales y performativos de la película.

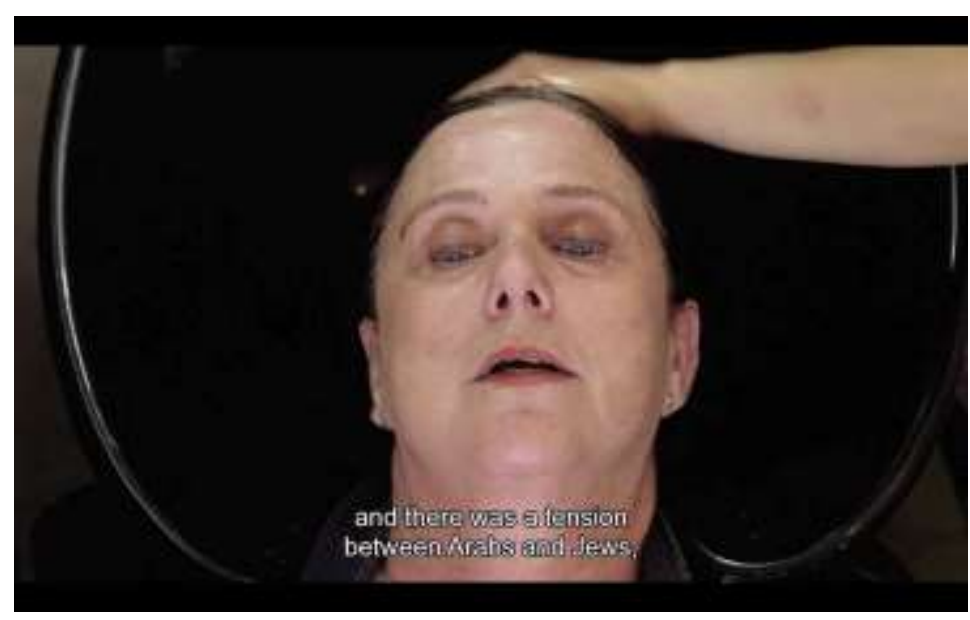

Fig. 4 Fotograma de Women In Sink (2015)

Por otro lado, el original plano sobre el que Zaki construye Women in Sink, plantea un interesante debate sobre cómo un exceso de estetización puede conllevar problemas de tipo ético, sobre todo cuando el trabajo trata cuestiones de representación como el que aquí atañe. La también cineasta y antropóloga, Ellie Lobovits, expone que, al decantarse Zaki por este plano, no tiene en cuenta la "gramática cinematográfica" (Lobovits, 2018) y el hecho de que en el cine cada plano tiene una implicación u otra. El plano cenital, es aquel tomado en perpendicular con respecto del suelo, dando un punto de vista desde arriba (el llamado ojo de Dios) y, aunque puede tener muchos usos narrativos, tradiconalmente se emplea para_remarcar la vigilancia o control sobre algo o la vulnerabilidad del personaje. Por lo que, colocar la cámara encima 
de las cabezas de las clientas en un plano cenital, implicaría cierta superioridad o distancia con respecto a ellas, y más teniendo en cuenta que ella es Israelí. Esto en teoría, porque en realidad, habría que señalar que la mayoría de las mujeres que aparecen en la película, en realidad, son también Israelís y, Lobovits obvia que la propia directora está lavándoles el cabello, no sólo el día que toma las imágenes sino durante un par de meses, por lo que la directora ya ha establecido una relación considerable con algunas de las clientas. Aun así, es interesante ver las consecuencias de elegir un dispositivo u otro y, cómo éste puede llegar a comunicar algo opuesto a lo deseado.

\subsection{Perfeccionando el método}

En su primer largometraje, Unsettling (2018), todavía de paso por varios festivales ${ }^{1}$, la realizadora Israelí se interna en Tekoa, uno de los más de 125 asentamientos israelíes sin reconocimiento legal en Cisjordania. Conocido por el estilo de vida "alternativo" de sus habitantes, no se distingue tanto de los demás en lo que se refiere a la cuestión nacional-religiosa. En medio de la colonia, Zaki instala algo parecido a un set televisivo: una mesa, unas sillas y tres cámaras fijadas a sus respectivos trípodes. Durante algo más de un mes, Zaki, que trabaja sola sin técnicos o ayudantes, despliega este dispositivo todos los días hasta que, lentamente, algunos de los habitantes de este particular asentamiento se acercan a charlar con ella.

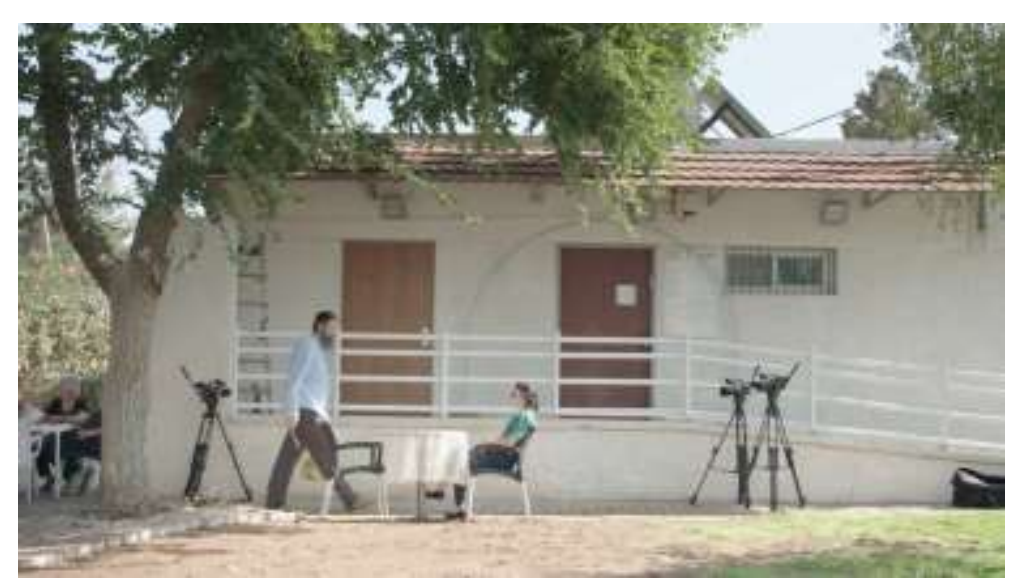

Fig. 3 Fotograma de Unsettling (2018)

Ya al comienzo de Unsettling, vemos como Zaki no es bienvenida. Matenya, único amigo de la realizadora en esta colonia con cerca de 4000 residentes, reprocha a la realizadora haberle hecho saber "a todo el mundo" que ella es de izquierdas, ya que, como la misma Zaki reconoce, fue una estrategia fallida; "Están paranoicos, no quieren hablar conmigo" (Zaki, 2018). A los residentes del asentamiento no parece entusiasmarles la idea de sentirse cuestionados ante una cámara por una progre de ciudad. Matenya, que llega a sentarse a charlar con Zaki hasta en tres ocasiones distintas y uno de los residentes con una visión más aperturista, se muestra decidido a llegar a algún tipo de acuerdo con los palestinos, aunque considera esencial vivir en un país judío. En cambio para Moriya, ex-hilltop youth (jóvenes extremistas que se establecen en puestos de avanzada) el problema no sólo son los árabes sino también los israelís de izquierdas. Moriya que achaca a la izquierda el derribo de su antigua casa, idolatra a los Kibutz (comuna agrícola) de antaño y, no entiende por qué ahora para una parte de la sociedad Israelí, ya no se ve bien seguir ocupando territorio palestino. Por otro lado, Michel, una religiosa ferviente que acaba de ser madre, a pesar de haber sido apuñalada por un palestino, aboga por crear un movimiento popular para establecer encuentros entre los colonos y los palestinos con el fin de establecer modelos de convivencia. $\mathrm{Y}$ así, otras tantas conversaciones que no dejan indiferente a nadie y que se entremezclan, por un lado, con imágenes que dejan ver el mecanismo o la parte procesual de la película: Zaki montando y desmontando el set,

\footnotetext{
1 Algunos de los festivales por los que ha pasado recientemente: BFI London Film Festival, New Horizons Film Festival, Poland, Ethnofest, Greece, Dokfest Munich, Germany, Santa Barbara International Film Festival, USA, CPH DOX, Denmark.
} 
conversaciones telefónicas con su pareja donde comentan el día a día de rodaje, etc.; y por otro lado, con imágenes que muestran el lugar: planos panorámicos del desierto, detalles del asentamiento, palestinos que cruzan el checkpoint cada día para trabajar en el lado Israelí, etc.

\section{Conclusiones}

Al igual que Eduardo Coutinho, Zaki no busca para sus películas un momento crítico; dónde acaba de pasar algo, o va a pasar algo, sino que lo que le interesa es hablar con la gente de sus vidas, en un día cualquiera. Pero, a diferencia del director Brasileño, para Zaki la película comienza antes de empezar a rodar, diseñando su dispositivo, delimitando el plan a seguir. Las diferentes estrategias que toma para realizar sus películas, la cámara abandonada, entrar a trabajar en diferentes establecimientos, dejar momentáneamente el "cine" a un lado, etc., le permiten introducirse en realidades y en comunidades a las que es difícil acceder, y que plantean desafíos importantes, como es el caso de los colonos en Cisjordania, donde la tensión se palpa en el ambiente, ya que los residentes del asentamiento han adquirido una aversión a las cámaras fruto de la imagen de extremistas y violentos que la gran mayoría de los medios dan de ellos. Pero además, estas maniobras o técnicas le ayudan a crear una dinámica orgánica (ella está realmente allí y no detrás de la cámara) que le permite tener conversaciones abiertas donde se muestra vulnerable, exponiendo su propia opinión, pensamientos y sentimientos.

Zaki no parece especialmente preocupada por los aspectos técnicos o el resultado de sus películas, de ahí que sea tan poco ortodoxa en los procedimientos (lo que otorga frescura y originalidad a sus films), sino que le interesa más la parte procesual y el debate que se crea en torno a las películas. Acostumbrada a recibir críticas de uno y otro lado, su última película estaba disponible online en Israel y, como era de imaginar, ha causado una gran polémica. Zaki, trabaja en salir de la polarización y trata de recoger las voces matizadas, que vayan más allá del blanco y el negro. Un trabajo arduo que también se hace necesario por estas tierras, sobre todo con la cuestión catalana de los últimos años, donde la división en dos bloques de la política y, también, de gran parte de la sociedad, requiere de voces intermedias que acerquen posturas y busquen el consenso. Su trabajo es una invitación a salir de las zonas de confort y de los prejuicios, un llamamiento al diálogo, a escuchar opiniones diferentes, sin miedo a debatir ideas por mucho que estas puedan ser diferentes a las tuyas, y que, como reflejan sus películas, siempre terminamos sorprendidos al descubrir que no somos tan distintos como pensamos.

\section{Referencias}

BISHOP, C. (2006). Participation. London: Whitechapel gallery and MIT press.

LOBOVITS, E. (2018). "Women in Sink Zaki, Iris, dir. 36 min. Hebrew with English subtitles. Israel: Go Films, 2015" en American Antnthropologist. Vol. 120, №1. 167-168. 〈https://www.academia.edu/36278906/Women_in_Sink_Film_Review> [Consulta: 3 de abril de 2019]

ZAKI, I. (2017). Open Conversation in Closed Communities. Tesis doctoral. Londres: Royal Holloway, University of London, <https://pure.royalholloway.ac.uk/portal/files/29837324/2018zakiiphd.pdf> [Consulta: 10 de junio 2019].

\section{Películas}

Chronique d'un été. (Crónica de una verano. Dir. Jean Rouch, Edgar Morin). Productora: Argos Films, 1961.

Lift. (Dir. Marc Isaacs). Productora: Dual Purpose Productions, 2001.

O quarto da Vanda. (Dir. Pedro Costa). Productora: Contracosta Poducçoes / IPACA / Pandora Film / TSI / Ventura Film / ZDF, 2000. My Kosher Shifts. (Dir. Iris Zaki), 2011.

Women in Sink. (Dir. Iris Zaki), 2015.

Unsettling. (Dir. Iris Zaki). Productora: Nutz Productions, 2018. 